\title{
FADD self-association is required for stable interaction with an activated death receptor
}

\author{
C Sandu ${ }^{1}$, G Morisawa ${ }^{1}$, I Wegorzewska ${ }^{1,3}$, T Huang ${ }^{1}$, \\ AF Arechiga ${ }^{2}$, JM Hill ${ }^{1}, \mathrm{~T} \mathrm{Kim}^{1,3}, \mathrm{CM}$ Walsh ${ }^{2}$ and MH Werner ${ }^{\star, 1}$ \\ ${ }^{1}$ Laboratory of Molecular Biophysics, The Rockefeller University, New York, NY, \\ USA \\ 2 Center for Immunology and Department of Molecular Biology \& Biochemistry, \\ University of California, Irvine, USA \\ ${ }^{3}$ Wegorzewska and Kim are medical students and their current addresses are \\ not known. \\ * Corresponding author: MH Werner, Laboratory of Molecular Biophysics, The \\ Rockefeller University, 1230 York Avenue, Box 42, New York, NY 10021, USA. \\ Tel: 212327 7221; Fax: 212327 7222; \\ E-mail: mwerner@portugal.rockefeller.edu
}

Received 29.12.05; revised 20.3.06; accepted 18.4.06; published online 19.5.06 Edited by ME Peter

\begin{abstract}
Receptor-mediated programmed cell death proceeds through an activated receptor to which the death adaptor FADD and the initiator procaspases 8 and/or 10 are recruited following receptor stimulation. The adaptor FADD is responsible for both receptor binding and recruitment of the procaspases into the death-inducing signaling complex. Biochemical dissection of the FADD death effector domain and functional replacement with a coiled-coil motif demonstrates that there is an obligatory FADD self-association via the DED during assembly of the death-inducing signaling complex. Using engineered oligomerization motifs with defined stoichiometries, the requirement for FADD self-association through the DED can be separated from the caspase-recruitment function of the domain. Disruption of FADD self-association precludes formation of a competent signaling complex. On this basis, we propose an alternative architecture for the FADD signaling complex in which FADD acts as a molecular bridge to stitch together an array of activated death receptors.

Cell Death and Differentiation (2006) 13, 2052-2061.

doi:10.1038/sj.cdd.4401966; published online 19 May 2006
\end{abstract}

Keywords: FADD; CD95; extrinsic cell death; oligomerization; self-association

Abbreviations: DRs, death receptors; DED, N-terminal death effector domain; DD, death domain; DISC, death-inducing signaling complex; TNFR1, tumor necrosis factor receptor 1; IC, intracellular domain

\section{Introduction}

The principal transducer of cell death signals at death receptors (DRs) is the Fas-associated death domain protein FADD. ${ }^{1,2}$ FADD is composed of two structurally similar motifs, an $\mathrm{N}$-terminal death effector domain (DED) and a C-terminal death domain (DD), ${ }^{3-5}$ which engages the DD of an activated death receptor through homotypic (i.e. DD-to-DD) interactions between receptor and FADD. ${ }^{6}$ The association of FADD with an activated DR subsequently recruits the initiator procaspases 8 and/or $10^{7-10}$ to create a death-inducing signaling complex (DISC). ${ }^{11}$

Despite knowledge of the DISC components, ${ }^{12}$ the molecular basis for protein-protein interaction and the stoichiometry of the DISC proteins has remained elusive. A minimal DISC is composed of three molecules of a DR ${ }^{13-15}$ but it is less clear how FADD engages the receptor, how many copies of FADD are in the DISC and whether procaspases 8 and 10 are bound to the same trimeric receptor via FADD. FADD is believed to use only its DD to engage the receptor ${ }^{16}$ even though FADD cannot be reconstituted with the receptor in the absence of the FADD DED (Zhang and Winoto ${ }^{17}$ and this report). Mutations in the DED disrupt FADD association with CD95 (Fas/Apo-1) ${ }^{18,19}$ and DR5 (Trail receptor 2) ${ }^{19}$ in conflict with the notion that only the FADD DD is required for receptor association. A deletion mutant of FADD lacking the DED, FADD dominant negative (DN-FADD, residues $80-208),{ }^{1,16}$ is inhibitory to CD95 and tumor necrosis factor receptor 1 (TNFR1)-mediated cell death in many contexts. ${ }^{16,17,20-22}$ Yet, DN-FADD cannot be observed by co-immunoprecipitation with a DR, ${ }^{17}$ suggesting that DN-FADD binds weakly to an activated receptor on its own. Thus, the FADD DED must play a role in stabilizing the receptor/adaptor complex during death signal transduction.

Here we show that FADD uses the DED to self-associate into an arrangement necessary to stabilize FADD at the intracellular domain of an activated DR. Analysis of DED mutants in a variety of contexts identified a surface for FADD self-association that can be separated from the caspaserecruitment function of the domain. We clarify the inhibitory capabilities of DN-FADD, illustrating that it is a poor inhibitor of CD95-mediated apoptosis. Using re-engineered, oligomeric FADD DDs, we create true dominant-negative FADD molecules capable of blocking FADD recruitment to the receptor. On the basis of these observations, the structure of intact $F_{A D D}^{23}$ and the pairing mechanism between FADD and its cognate receptor ${ }^{24}$ we describe an alternative organization for the DISC in which we propose FADD acts as a molecular bridge between activated DRs.

\section{Results}

\section{FADD DD is necessary, but not sufficient for association with a death receptor}

To explore the mechanism of FADD interaction with CD95, the complex of these proteins was reconstituted in several contexts. Full-length FADD was efficiently pulled down with the intracellular domain (IC) of CD95 (GST-CD95 IC) (Figure 1a), but neither FADD DD nor FADD DED alone could reconstitute this interaction; mixing the individual 

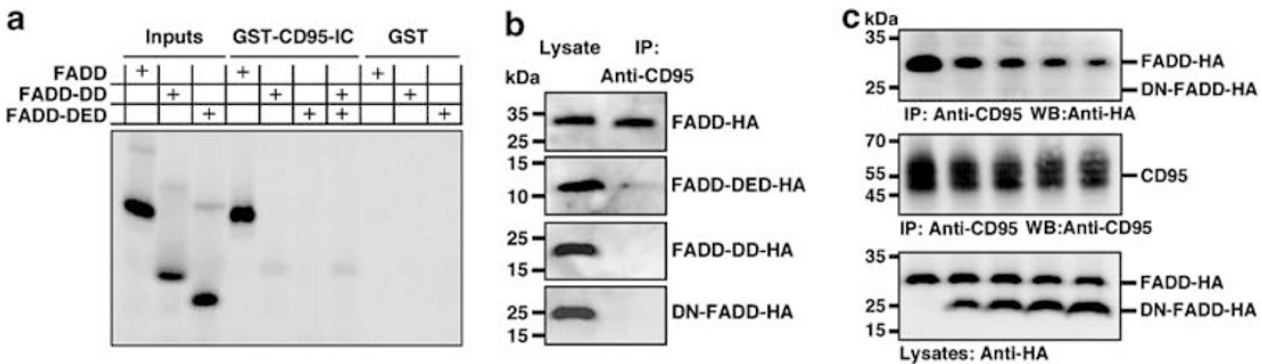

Figure 1 Interaction of FADD and its individual domains with CD95. (a) GST-CD95 IC pull-down of FADD and its domains. The 'Inputs' panel shows the expression of each deletion mutant protein resulting from coupled in vitro transcription/translation. The next 4 lanes show the interaction between GST-CD95 IC and $\left.{ }^{35} \mathrm{~S}\right]-$ Met labeled FADD, FADD DD, FADD DED or a mixture of FADD domains individually expressed (DD + DED). In the last 3 lanes, FADD, FADD DD and FADD DED were assessed for their interaction with GST alone. (b) Analysis of CD95 and FADD interaction, assessed by immunoprecipitation. FADD, FADD DD, FADD DED and DN-FADD were transiently expressed in MCF7-Fas cells and immunoprecipitated with an anti-CD95 antibody (Apo 1-3) as described in Material and Methods. The FADD proteins were detected by western blotting (WB) with an anti-HA antibody. (c) DN-FADD is poor competitor against FADD at CD95. Wild-type FADD was co-expressed with increasing quantities of DN-FADD (bottom panel) in MCF7-Fas cells and their ability to interact with CD95 was tested by immunoprecipitation with the Apo 1-3 antibody (top panel). DN-FADD is not observed to be associated with CD95 in the IP fraction. The proteins were visualized by western blotting with an anti-HA antibody

domains with GST-CD95 IC did not restore an interaction with receptor in this assay (Figure 1a). Similarly, only full-length FADD can co-immunoprecipitate (co-IP) with the CD95 DISC from MCF7-Fas cells ${ }^{25}$ (Figure 1b). Thus, the domains of FADD must be covalently linked in order to reconstitute the interaction with CD95.

The requirement for the FADD DED in receptor association is at odds with the reported phenotype of DN-FADD. ${ }^{16,17,20-22}$ DN-FADD has been thought to bind the CD95 DD, saturate FADD binding sites at the receptor and block full-length FADD from gaining access to receptor binding sites. As DN-FADD lacks most of the DED, it would also be unable to engage the initiator procaspases to transduce a death signal into a biochemical response. Thus, FADD DED should have no role in receptor association as procaspases are not required to reconstitute an interaction between FADD and CD95. ${ }^{26}$ Experimentally, however, FADD DED must be linked to FADD DD for a productive interaction with the receptor in vitro and in cell culture (Figure 1a,b). To resolve this conundrum, full-length and DN FADD were co-expressed in MCF7-Fas cells, revealing that only full-length FADD could immunoprecipitate with CD95 following 10 min stimulation with Apo 1-3 (Figure 1b). This was true even when the expression of DN-FADD was significantly higher than that of the full-length protein in the same context (Figure 1c). DN-FADD could chase some FADD from receptor binding sites, but did so at a level below its level of expression in the same cell (Figure 1c). These experiments indicated that DNFADD binds more weakly to CD95 relative to the full-length protein. This was not an artifact of overexpression or a competition between the transiently expressed and endogenous full-length proteins in these cells. The DD of FADD is therefore necessary, but not sufficient, for stable FADD association with the receptor.

In Jurkat A3 cells stably transfected with DN-FADD, expression of DN-FADD at physiological levels failed to suppress CD95-mediated cell death (Figure 2a,c), arguing against a role for DN-FADD as a dominant inhibitor. To assess the integrity of DN-FADD expressed in these cells, its ability to inhibit TNFR1-mediated cell death was also measured. As FADD requires only its $D D$ to interact with TRADD during the assembly of the TNFR1-associated DISC, ${ }^{24}$ it was expected, and observed, that DN-FADD would act as a competitive inhibitor of TNF $\alpha$-stimulated cell death (Figure 2b). While it has been repeatedly shown that DN-FADD can protect cells from a Fas ligand (FasL) stimulus, this is usually observed when DN-FADD is expressed at levels significantly higher than endogenous levels of the full-length protein. This is true even in transgenic mice, where targeted expression of DN-FADD protected thymocytes and other cells of lymphoid origin from apoptosis induced by treatment with FasL. ${ }^{20-22}$ The relative level of expression of FADD and DN-FADD in thymocytes is at least $1: 100$ (Figure 2d), indicating that when the transgene is expressed, DN-FADD is present at dramatically higher levels relative to the endogenous, full-length protein. Therefore, DN-FADD is a poor competitor for FADD binding sites at an activated DR.

\section{FADD DED is required for receptor association}

To determine the role of the FADD DED in receptor association, GST or trimeric CD95 ${ }^{26}$ IC pull-down of fulllength FADD was performed in which selected positions in the DED had been mutated (Figure $3 a$ ). A number of positions in the DED led to a loss of receptor binding, including residues in helices 2 and 3 (F25, L28 and K33) as well as in helix 5 (A68D). Ectopic expression of these DED mutants in MCF7Fas cells reinforced a role for the FADD DED in CD95 interaction (Figure $3 \mathrm{~b}$ and supplemental data). Although MCF7 cells lack caspase-3, they nonetheless form 'typical' DISCs associated with receptor-mediated cell death. ${ }^{12}$ Thus, in this setting, positions in the FADD DED that are deficient in receptor association by reconstitution also fail to transduce a death stimulus when ectopically expressed in cell culture.

The DED mutants were also tested for their ability to interact with the initiator procaspases. Mutations at F25 and K33, which fail to associate with CD95 (Figure 3a) or support CD95mediated cell death (Figure $3 b$ ), ${ }^{23}$ have also been reported to participate in procaspase- 8 recruitment into the DISC. ${ }^{3,27}$ To investigate this observation further, the soluble 'Complex II' formed between FADD, TRADD, TRAF2 and RIP was investigated. ${ }^{28}$ This complex displays no dependence on the 

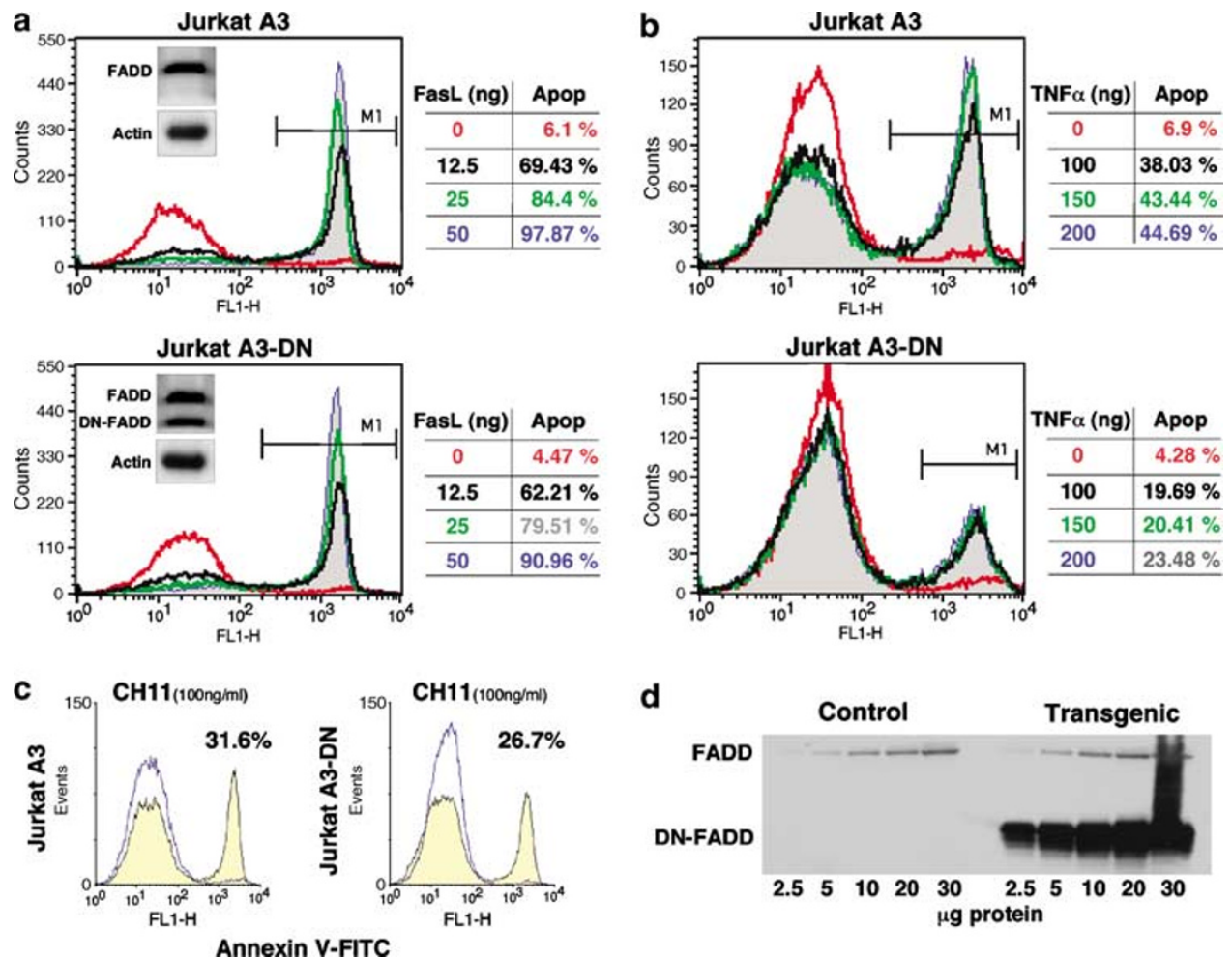

Figure 2 Analysis of FasL and TNF $\alpha$-induced apoptosis in Jurkat A3 cells stably expressing DN-FADD. Jurkat A3 cells and Jurkat A3 cells stably transfected with DNFADD (Jurkat A3 DN-FADD) were analyzed for their ability to undergo apoptosis following treatment with varying amounts of FasL (a) or TNF $\alpha$ (b) or anti-CD95 (CH-11) (c). Endogenous FADD expression was comparable to DN-FADD expression in Jurkat A3 DN-FADD cells as measured by WB with anti-FADD (see insets). Following treatment with FasL or TNF $\alpha$, the cells were stained with FITC-Annexin V and the percentage of apoptotic cells was measured by flow cytometry. (d) Abundance of DNFADD vs endogenous FADD in thymocytes of transgenic DN-FADD mice. ${ }^{21}$ Thymocytes from normal and transgenic mice were tested for DN-FADD and wild-type FADD expression by western blotting with an anti-FADD antibody

FADD DED for the interaction between TRADD and FADD (Figure 3C). Several of the receptor binding-deficient DED mutations (F25R, L28R, K33E, D74A) also failed to interact with procaspase-8 in this context (Figure $3 d$ ). However, two mutants, D44R and E51K, retained their ability to associate with CD95 (Figure 3a) and TRADD (Figure 3d), despite the loss in procaspase-8 interaction (Figure 3d). Thus, two classes of mutations are evident from this analysis. One class affected all FADD DED functions (F25, L28, K33, D74), while the second class (D44 and E51) had a defect that was specific for the procaspases. ${ }^{23}$ Both classes of mutants failed to respond to TNF $\alpha$ treatment in stably transfected FADDdeficient Jurkat I2.1 cells (Figure 3e). As the DED mutants F25R, L28E, K33E and D74A were defective in all FADD functions, they must define a surface of FADD that plays a more fundamental role in DISC assembly than receptor or procaspase interaction. We considered whether some or all of these residues were involved in FADD self-association, as suggested by structural studies of FADD, which required the mutation F25Y for soluble FADD protein to be prepared at high concentrations. ${ }^{3,23}$

\section{FADD DED mediates oligomerization of FADD}

GST pull-down revealed that the FADD DED mediates an interaction between full-length FADD and itself (Figure 4a). FADD self-association was not dependent on the C-terminal tail of FADD nor on phosphorylation at S194, as FADD can be truncated to residue 183 (termed FADD-NT) without disruption of FADD self-association (Figure 4a). To identify the surface of FADD self-association, GST-FADD-NT mutated in the DED was used to pull-down wild-type FADD labeled with $\left[{ }^{35} \mathrm{~S}\right]-$ Met (Figure $\left.4 \mathrm{~b}\right)$. Three of these mutants, F25R, L28E and K33E, failed to self-associate. By contrast, A68D, R72A and D74A displayed only modest defects in this assay. D44R, which had a caspase-specific binding defect (Figure 3d), was normal for the association of FADD with itself.

To demonstrate that FADD self-association is separable from the interaction with the procaspases, the FADD DED was replaced with a coiled-coil motif capable of forming dimers or trimers of the FADD DD (residues 89-208). A dimeric, leucine zipper (LZ) coiled-coil was placed $\mathrm{N}$-terminal to the FADD DD, creating LZ-FADD-DD. A C-terminal hemagluttinin (HA) tag was added to aid in the observation of the engineered protein by Western blot. A variant of this design, IZ-FADD-DD, appended the DD with a trimeric, isoleucine zipper (IZ) variant. ${ }^{29}$ Each of these engineered oligomers was expressed in MCF7-Fas cells and their ability to associate with CD95 assessed by receptor stimulation with Apo 1-3 for $10 \mathrm{~min}$, followed by CD95 immunoprecipitation and Western blotting with anti-HA. In contrast to monomeric (i.e. DN) FADD (Figure 1c), oligomerized FADD DD can co-IP with CD95 (Figure 4c). This effect was specific to the FADD DD as a DD mutant incapable of receptor binding, ${ }^{26} \mathrm{R} 113 \mathrm{E}$, disrupted the 
a

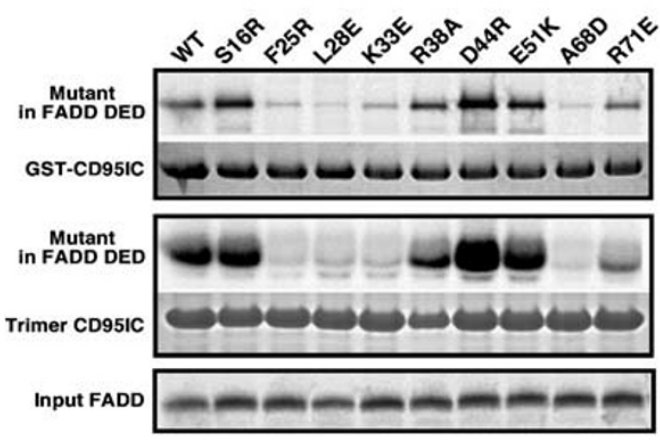

b

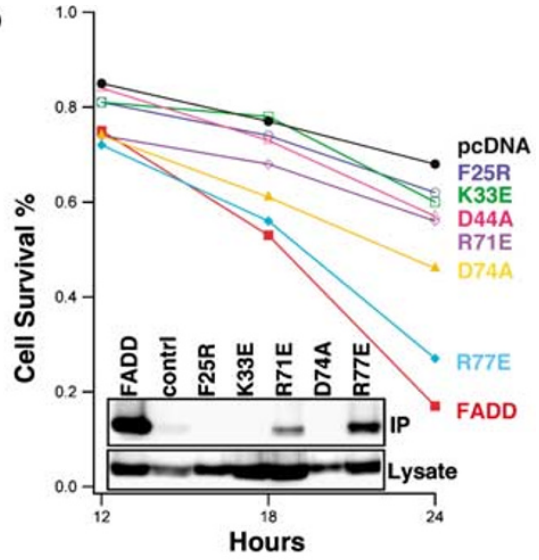

C

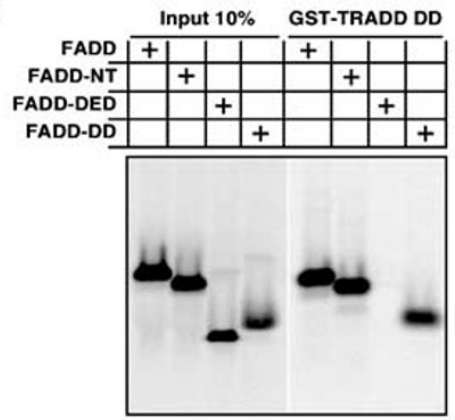

d

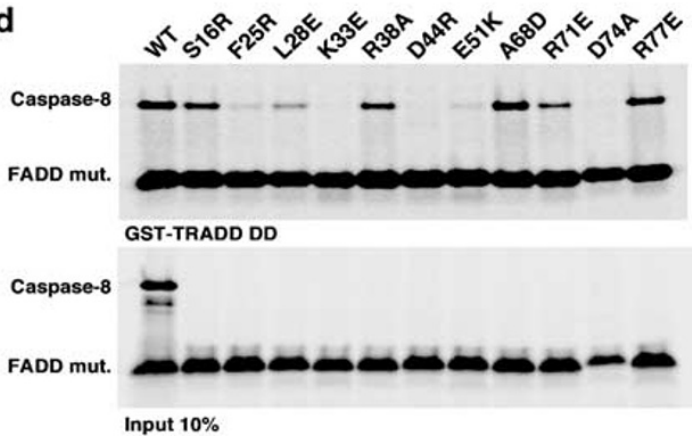

Input $10 \%$ e

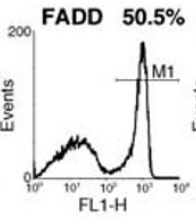

F25R 10.1\%

Anne

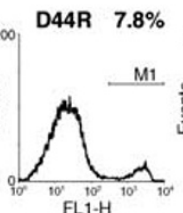

Figure 3 Mutating the FADD DED disrupts receptor and procaspase-8 interaction. (a) GST pull-down assay between GST-CD95 IC or an enforced trimer of CD95 IC (Timer CD951C) ${ }^{26}$ with [ ${ }^{35}$ S)-Met labeled full-length FADD mutants. (b) Effect of mutation in FADD DED on CD95-mediated cell death in MCF7-Fas cells (see Materials and Methods). Mutants that are deficient in CD95 binding are also deficient in CD95-mediated cell death and fail to co-IP with CD95 (see inset). (c) GST pull-down assay between GST-TRADD DD and [ $\left.{ }^{35} \mathrm{~S}\right]$-Met-labeled FADD or FADD deletion mutants. FADD DD is necessary and sufficient for the interaction with TRADD. ${ }^{24}$ (d) GST pulldown assay between GST-TRADD DD and $\left[{ }^{35} \mathrm{~S}\right]$-Met-labeled full-length FADD or FADD mutant and $\left[{ }^{35} \mathrm{~S}\right]-$ Met-labeled full-length caspase-8 C360S (top panel). Lower panel shows the $10 \%$ input for each FADD mutant and procaspase-8 C360S. In this case, a single transcription/translation reaction was run for procaspase-8 C360S, with sufficient quantity for inclusion in all 12 lanes, but shown in only one lane. For FADD or FADD mutant, each mutant was expressed in an individual reaction. (e) Effect of FADD DED mutation on TNF $\alpha$-stimulated apoptosis. Analysis of apoptosis by flow cytometry of Jurkat I2.1 (FADD ${ }^{-l-}$ ) cells stably transfected with FADD mutants, as described in Materials and Methods. Mutants defective in receptor and caspase association (F25R) or only caspase association (D44R) are also defective in cell death. A68D displays intermediate phenotypes, as described in the text

co-IP with CD95 for both the LZ- and IZ-FADD-DD variants (Figure 4c). Analysis of cell death by flow cytometry in Jurkat I2.1 cells, in which wild-type FADD was transiently coexpressed with either LZ- or IZ-FADD-DD, demonstrated that oligomerized FADD DD is also an efficient inhibitor of apoptosis (Figure 4d). R113E, on the other hand, reversed this effect.

Transfection of increasing quantities of the expression vector for DN-FADD into MCF7-Fas cells displaced FADD from CD95, but does not lead to stable association of DNFADD with CD95 following Apo 1-3 stimulation (Figure 1c). Titration of the expression vector for either LZ-FADD-DD or IZ-FADD-DD led to both observable competition for FADD binding sites and co-immunoprecipitation with CD95 (Figure $4 \mathrm{e}, \mathrm{f})$, indicating that LZ/IZ-FADD-DD forms a tighter interaction with CD95 relative to monomeric FADD DD. Collectively, these observations argue that the FADD DED mediates a selfassociation function that is essential for stable interaction with activated CD95.

The efficiency of inhibition by LZ/IZ-FADD-DD was assessed by ectopic expression in Jurkat 12.1 cells. When overexpressed, DN-FADD protects approximately $50 \%$ of transfected cells from FasL-stimulated cell death (Figure $5 a, b)$. LZ-FADD-DD, despite being expressed at a lower level relative to the full-length protein, protects approximately $70 \%$ of transfected cells from the effects of FasL (Figure $5 \mathrm{c}$ ). IZFADD-DD is even more efficient, providing nearly complete protection from apoptosis (Figure $5 \mathrm{~d}$ ). All three forms of FADD DD were also stably transfected into HEK293 cells under control of a tetracyline-inducible promoter. The time course of protein expression suggested that between 0 and $5 \mathrm{~h}$, DNFADD, LZ-FADD-DD and IZ-FADD-DD were equal to or less 
a
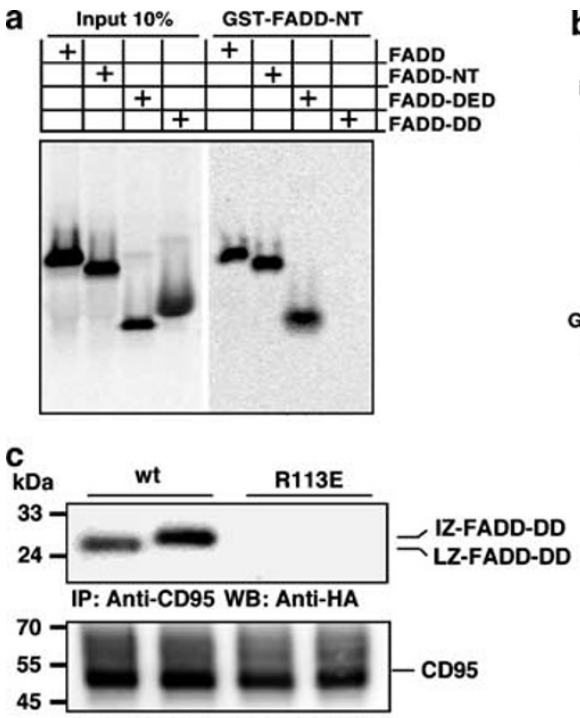

IP: Anti-CD95 WB: Anti-CD95
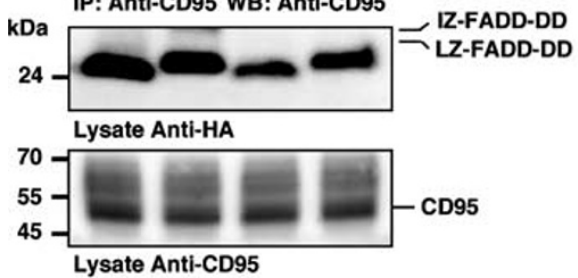

e
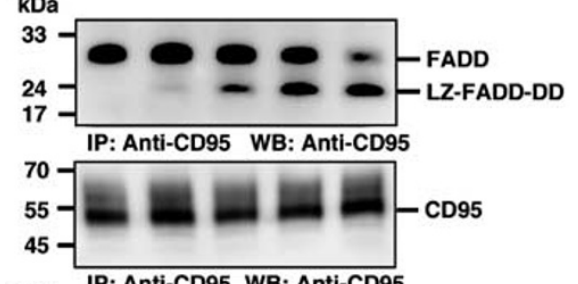

IP: Anti-CD95 WB: Anti-CD95

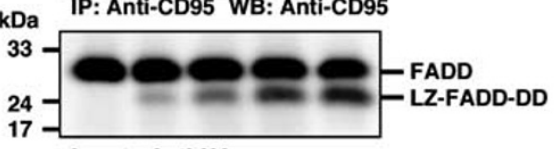

b

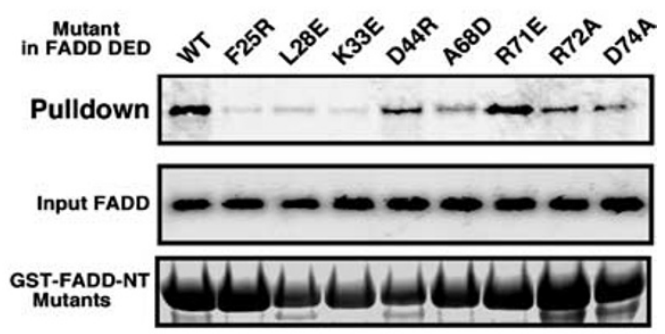

d
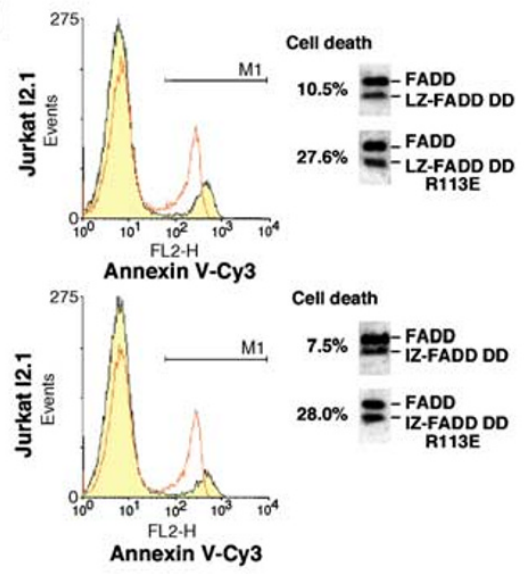

f $\mathrm{kDa}$
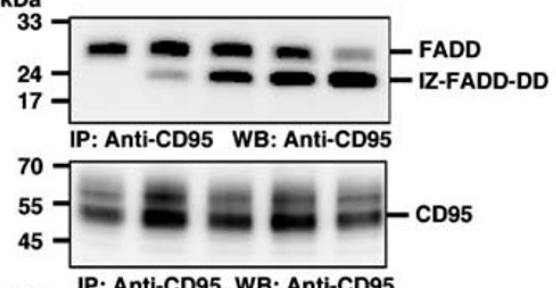

kDa

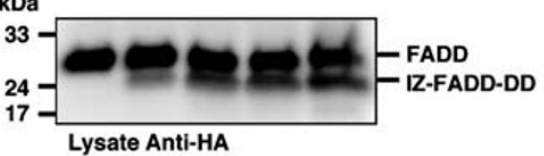

Figure 4 Oligomerized FADD DD substitutes for FADD DED to associate with CD95. (a) GST pull-down assay between GST-FADD NT and FADD deletion mutants. FADD DED is necessary and sufficient for interaction with FADD and independent of the C-terminal tail of (residues 192-208), which includes the site of phosphorylation at S194. (b) GST pull-down of mutant FADD-NT with wild-type full-length FADD, as indicated. (c) Co-immunoprecipitation of LZ- or IZ-FADD-DD with CD95 following ectopic expression in MCF7-Fas cells. Introduction of the R113E mutation into the FADD DD constructs disrupted the co-IP, indicating that the association with CD95 was specific for the FADD DD. (d) LZ- and IZ-FADD-DD dominantly inhibits apoptosis following ectopic co-expression with wild-type FADD in FADD-deficient Jurkat I2.1 cells. Introduction of the R113E mutation into the FADD DD failed to inhibit apoptosis measured by flow cytometry with Annexin V-Cy3. (e) MCF7-Fas cells were stimulated with Apo 1-3 for 10 min before anti-CD95 immunoprecipitation. FADD and dimeric LZ-FADD-DD co-IP with CD95 (upper pane), in contrast to the behavior of DN-FADD (Figure 1c). Lower panel shows the expression level of FADD and LZ-FADD-DD in cell extracts, visualized by WB with anti-HA. (f) Co-immunoprecipitation of FADD and trimeric IZ-FADD-DD with CD95 from MCF7-Fas cells following activation with Apo 1-3 (upper panel). Bottom panel shows the expression level of FADD and IZ-FADD-DD in cell extracts

abundant than endogenous FADD in these cells. Both LZ- and IZ-FADD-DD efficiently inhibited apoptosis following inducible expression for $5 \mathrm{~h}$ as detected by cell morphology and Hoechst staining of degraded chromatin (Figure 5e). DNFADD was a less-efficient inhibitor of cell death at physiological levels of expression. Thus, replacing the FADD DED with an oligomerization motif enables stable association between FADD DD and activated CD95, leading to dominant inhibition of receptor-mediated cell death.

\section{Discussion}

Mutagenesis of FADD and biochemical investigation in a variety of contexts has established that individual domains of FADD cannot support CD95-mediated cell death or stably associate with CD95 on their own. We (Figures 3-5), and others, ${ }^{17}$ have shown that DN-FADD, although inhibitory to apoptosis, cannot act as a stoichiometric inhibitor of receptormediated cell death. DN-FADD tends to be effective only 
a

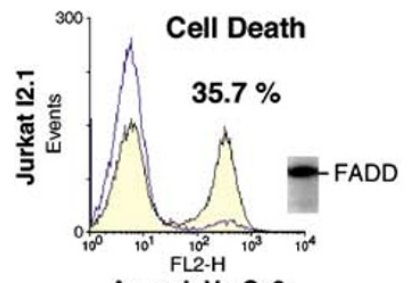

AnnexinV - Cy3

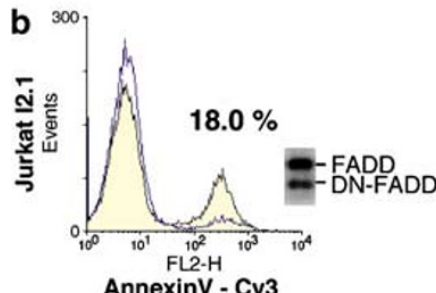

AnnexinV - Cy3

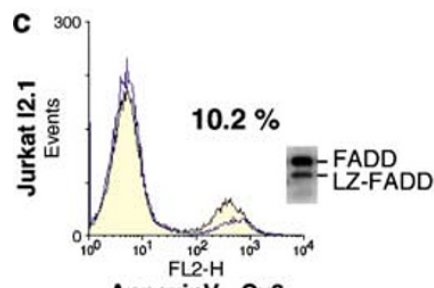

AnnexinV - Cy3

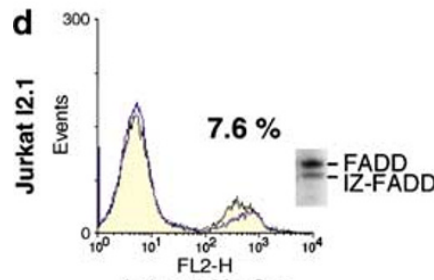

AnnexinV - Cy3 e

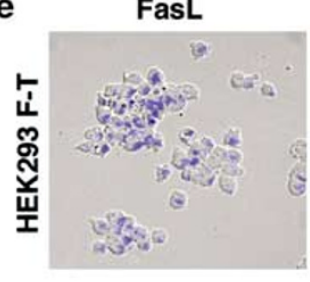

no activation
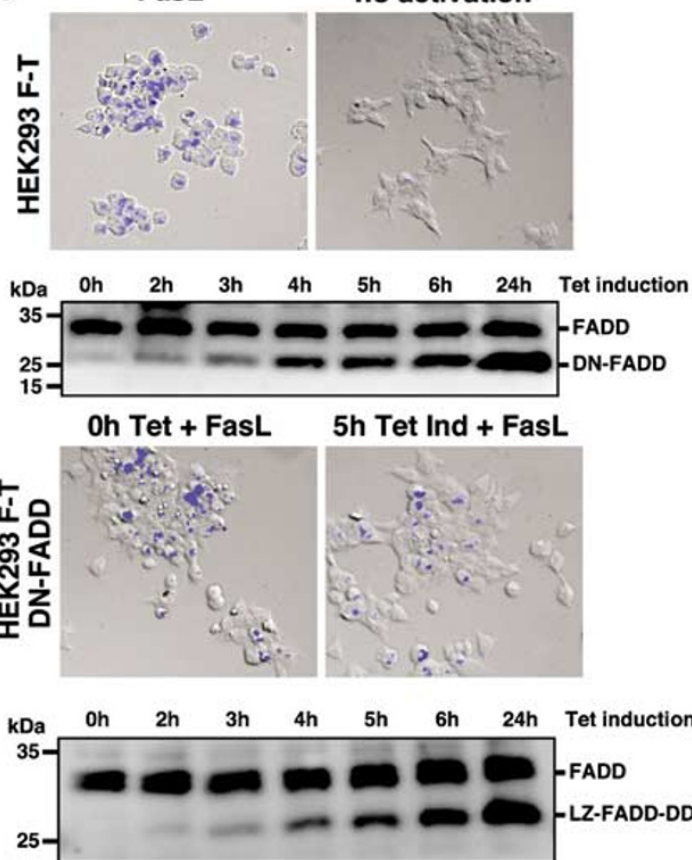

Oh Tet + FasL
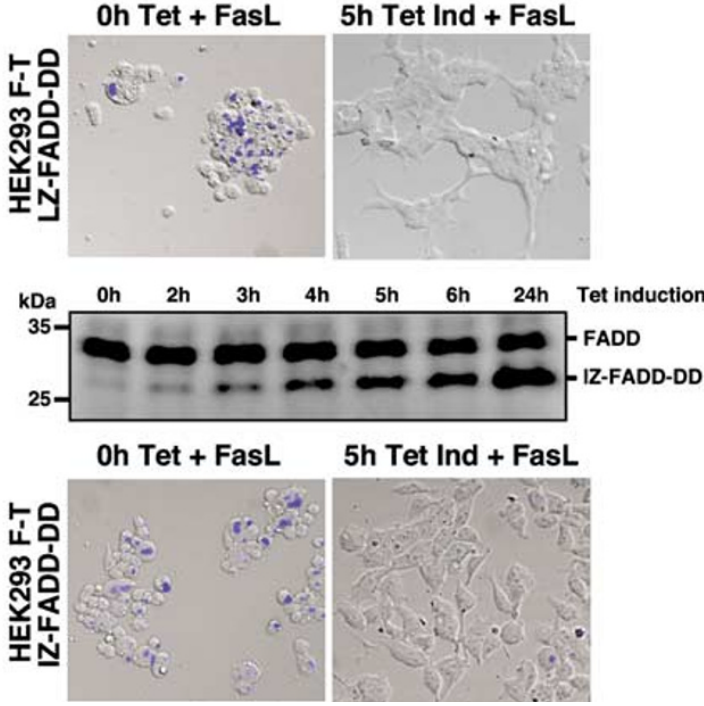

Figure 5 Oligomerized FADD DD is a dominant inhibitor of CD95-mediated cell death. Panels (a)-(d) reflect flow cytometry analysis of FasL-stimulated cell death following transient expression of the indicated proteins. The overlay in each panel compares unstimulated cells with FasL-treated cells. Note that the apparent level of cell death for non-stimulated cells varies slightly from panel to panel. The percentage of dead cells reported represents the difference between the level of cell death observed for the FasL-treated cells, less the observed level of spontaneous cell death for untreated cells subsequent to transient transfection. (a) $35.7 \%$ of GFP-positive cells undergo cell death following ectopic expression of FADD in Jurkat I2.1 (FADD $\left.{ }^{-1-}\right)$ cells and stimulation with FasL. (b) When DN-FADD and full-length FADD are ectopically co-expressed, only $18 \%$ of the GFP-positive cells die. (Note that the western blots between Figure $2 \mathrm{a}$ and this figure cannot be directly compared due to the differences in the percentage of cells expressing the indicated proteins in each case. In stably transfected Jurkat A3 cells (Figure 2a), all cells express FADD and DNFADD, but in transiently transfected Jurkat I2.1 cells, only $\approx 10 \%$ of the cell population is expressing FADD and the different DD constructs.) (c) LZ-FADD-DD and (d) IZFADD-DD-expressing cells have significantly lower levels of protein expression relative to full-length FADD (see insets), but are substantially better protected against FasL-stimulated cell death. (f) Inducible expression of DN-FADD, LZ-FADD-DD and IZ-FADD-DD differentially suppresses apoptosis in HEK293 cells. The time course of expression was followed by anti-FADD Western blot of endogenous FADD and the indicated DD construct following induction with tetracycline. At $5 \mathrm{~h}$, the level of inducibly expressed protein was equal to or less than the amount of endogenous FADD protein in these cells. DN-FADD provides modest protection against cell death following FasL administration, while both LZ-FADD-DD and IZ-FADD-DD appear to dominantly inhibit apoptosis measured by cell morphology and Hoechst staining

when overexpressed (Figure 2d) or when DN-FADD is present in significant excess over the quantity of $D R$ in a given cell type. Thus, the FADD DED is required for stable association with an activated DR. Mutagenesis of the FADD DD and DED revealed not only the likely surfaces of the protein necessary for interaction with the receptor $^{4,18,19,23,26,30}$ and the initiator procaspases (Figure 3), but also suggested that part of the DED serves a 'universal' purpose for FADD function. This 'universal' surface encompasses portions of the second and third $\alpha$ helices, to include 
F25, L28, K33 (Figure 4) and possibly Q34 and K35. ${ }^{27} \mathrm{We}$ hypothesize that this 'universal' surface is responsible for FADD-FADD interaction in the DISC. First, mutation of F25R, L28E or K33E, none of which disrupt the fold of the FADD $\mathrm{DED},{ }^{23}$ can abolish FADD-mediated signal transduction (Figure 3). Second, these mutants are also defective in procaspase-8 association in multiple contexts (Figure 3). ${ }^{3,23,27}$ As pre-association between FADD and procaspase- 8 or -10 is not required for FADD recruitment to activated CD95, ${ }^{31,32}$ the receptor and procaspase-binding deficiency observed for these mutants implies that they are reporting on a function intrinsic to FADD itself.

Several mutants we investigated displayed intermediate defects in protein-protein interaction. A68D failed to pull down with GST-CD95IC (Figure 3a), but is normal for FasLmediated apoptosis in Jurkat 12.1 cells (see Supplemental Figure 1). R71E binds more weakly to GST-CD95 (Figure 3a) and procaspase-8, (Figure $3 \mathrm{~d}$ ), and is less efficient at cell death (Figure $3 b$ ). The same mutant binds normally to GSTFADD (Figure 4b) and GST-TRADD (Figure 3d). Another mutant, D74A, is modestly defective at cell death when overexpressed (Figure 3b), binds GST-TRADD normally in a pull-down experiment (Figure 3d), but does not co-associate with CD95 by co-IP (Figure 3b) nor bind procaspase-8 in a pull-down experiment (Figure 3d). A68D, R72A and D74A are also less efficient at FADD self-association relative to wild type (Figure 4b). Thus, A68D, R71E, R72A and D74A display inconsistent phenotypes, perhaps indicating that this region of the DED does not tolerate site-directed mutagenesis well. Recent evidence suggests this region of the DED plays a role in stabilizing the fold of the domain. The crystal structure of the viral FLICE-inhibitory protein $\mathrm{MC} 159^{33,34}$ revealed that T163, R166 and D168 (equivalent to FADD A68, R72 and D74) forms intra-domain contacts essential to the DED fold. The $\mathrm{C}^{\gamma 2} \mathrm{H}_{3}$ of $\mathrm{T} 163$, for example, packs against $\mathrm{F} 118$ in MC159, equivalent to the interaction between A68 and L23 in FADD DED. ${ }^{3,23}$ Similarly, R166 in MC159 hydrogen-bonds with E111 and D168 in MC159, just as R72 would be predicted to interact with E19 and D74 in FADD. ${ }^{3,23}$ These interactions are predicted to stitch together the helix-loop-helix elements of helices 1 and 2 to helices 5 and 6 to stabilize the DED fold.

Our identification that the FADD self-association surface includes residues F25, L28 and K33 (the so-called 'hydrophobic patch'3) contrasts a recent report in which FRET was used to examine the interaction between FADD and itself. ${ }^{35}$ FRET between FADD-YFP and FADD-CFP can be disrupted by mutation of FADD in the RXDL $\phi$ motif (residues 72-76). ${ }^{35}$ However, NMR spectroscopy demonstrates that the point mutants R71E and R72A significantly alter the stability of the FADD protein, ${ }^{23}$ suggesting that the loss of FADD selfassociation by mutation in RXDL $\phi$ appears to be secondary to a loss in protein integrity. The same conclusion can be drawn from the introduction of D74A into the DED of the phosphoprotein enriched in astrocytes, PEA-15. ${ }^{36}$ In PEA-15, the interaction between ERK2 and PEA-15 D74A is lost and the NMR spectrum indicates that the overall stability of the mutant protein is significantly altered by the mutation, despite retention of its secondary structure. ${ }^{36}$ Mutations at FADD F25 and K33, on the other hand, have no significant effect on the protein fold or stability, ${ }^{23}$ but disrupt the interaction between FADD and CD95 (Figure 3), FADD and procaspase-8 (Figure 3$)^{23}$ and FADD with itself (Figure 4 ). It is interesting to note that while FADD and PEA-15 DED both possess the conserved RXDL $\phi$ motif, PEA-15 does not selfassociate even at millimolar concentration. ${ }^{36}$ FADD DED, but not PEA-15 DED, contains the 'hydrophobic patch' in the vicinity of F25 that we implicate to be the FADD selfassociation surface.

By functional replacement of the FADD DED with an oligomerization motif, we have demonstrated that an enforced dimer or trimer of the FADD DD can now act as an effective competitor against full-length FADD for receptor binding sites. We have demonstrated, therefore, that the FADD DED serves two purposes in DISC formation. One purpose is to recruit procaspase- 8 into the signaling complex and a second purpose is to build a higher-order structure of FADD molecules simultaneously engaged with each other and with activated receptor. In cells, FADD oligomers only form simultaneously with FADD/CD95 complexes at physiological levels of expression. Overexpression of FADD does not spontaneously activate cell death in many contexts, ${ }^{26}$ arguing against a pre-formed oligomer of FADD molecules at physiological concentrations (Figure 5a, Supplementary Figure 2). ${ }^{26}$ This suggests that both the FADD/FADD and the FADD/CD95 interaction are relatively weak interactions at the domain level and unable to assemble a competent signaling complex on their own. Collectively, however, these interactions are additive, enabling simultaneous association between FADD and the activated receptor as well as FADD with itself. This arrangement of FADD molecules could form in one of two ways.

In the typical model of the FADD-CD95 interaction (Figure 6), FADD forms a $3: 3$ complex with CD95 in which the FADD DDs engage their complements in the receptor. We append to this model self-association between FADD DEDs, which would engage one another within a single, activated receptor trimer (Figure 6a). However, as a specific arrangement of FADD DEDs is probably necessary to form the correct architecture of a FADD/CD95 complex, an intra-trimer complex between FADD and receptor would not explain why dimeric FADD DD is able to both associate with CD95 and compete with full-length FADD for receptor binding sites (Figure 4). An alternative arrangement that can meet this requirement suggests that FADD bridges between receptor trimers (Figure $6 \mathrm{~b}$ (see also Chang et $\left.a \beta^{37}\right)$ ). Although both models result in a $3: 3$ arrangement for FADD:CD95, bridging FADD molecules between trimers in our speculative model would stitch together neighboring receptors into higher-order clusters (Figure 6c). That such clusters form has been known for some time. ${ }^{31,32}$ Signaling 'SPOTS', 31 as well as receptor 'caps', 32 are dependent on FADD, but not procaspase-8. Moreover, when FasL is crosslinked into a dimer of trimers, the signaling efficiency is enhanced 1000 -fold, ${ }^{38}$ suggesting that activating cell death occurs through higher-order structures of receptor/ FADD complexes in which neighboring receptor trimers can potentiate the response. In our model of the receptor/adaptor complex, the FADD DEDs from neighboring trimers form a surface of interaction that brings together two procaspase-8 and/or -10 binding sites. Thus, the stoichiometry of the receptor complex is reduced from 3 to 2 as part of the process 


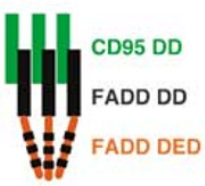

b
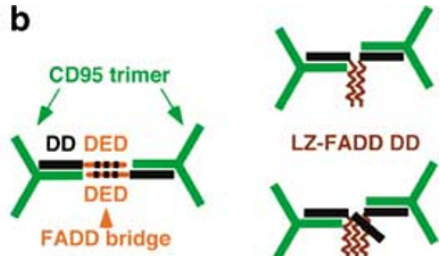

LZ-FADD DD

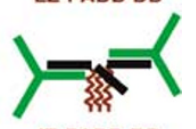

IZ-FADD DD

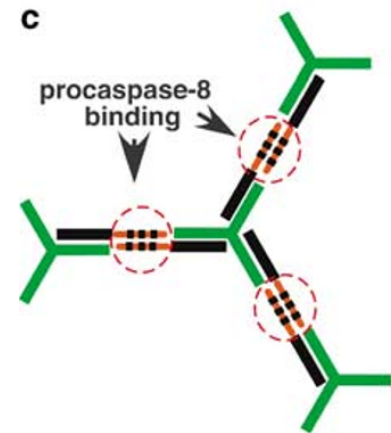

d

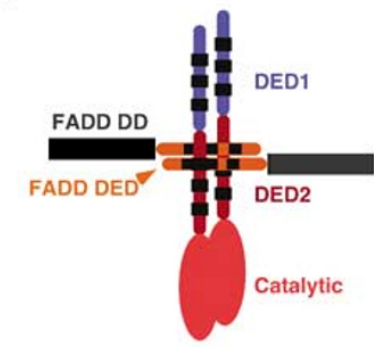

Figure 6 A new model for FADD-mediated assembly of the CD95 DISC. (a) Typical model of FADD associated with an activated CD95 trimer. The intracellular domain of CD95 is shown in green, the DD of FADD in black and the $D E D$ of FADD in orange with black stripes. To accommodate the observation of FADD self-association via the DED, a trimer of FADD molecules is shown. However, a dimer of FADD molecules could not form a complete self-association complex as compared to the trimer, and there is no evidence that FADD can discriminate between one or more molecules of CD95 in the complex. Therefore, this model would not explain how dimeric LZ-FADD-DD engages CD95 to act as a potent inhibitor of FasL-stimulated cell death. (b) An alternative arrangement suggests that FADD bridges between activated receptor trimers. Each intracellular domain of CD95 would be occupied by a molecule of FADD (although only one FADD per trimer is shown for clarity), with the FADD DED acting as both a surface for self-association and a surface for procaspase interaction. In this configuration, both the dimeric (LZ-FADD) and trimeric (IZFADD) constructs of the FADD DD could be accommodated as potent inhibitors of FasL-stimulated cell death. (c) Model of bridging FADD molecules building an array with three molecules of FADD bound per activated trimer. Procaspase interaction with the CD95/FADD complexes is represented by an orange circle to illustrate that the procaspases engage the clustering FADD molecules between activated receptors (see also Chang et $a^{\beta 7}$ ). This model may explain why FADD, which is always present in a cell, fails to activate cell death in the absence of a receptor stimulus. FADD must first localize to activated CD95 and bridge between activated receptors. This is consistent with the molecular ordering of events leading to procaspase activation. In the absence of receptor association, FADD cannot form the correct configuration necessary for procaspase binding and activation. Given that there is at most one procaspse binding surface per FADD molecule, ${ }^{23,24,26}$ the presence of dimeric FADD bridges may also account for the dimeric arrangement predicted for procaspase activation in the DISC. ${ }^{37,39,40}$ (d) Hypothetical detail of FADD bridges based on the identification of the procaspase- 8 binding surface in $F A D D^{23}$ and the suggestion that only the second prodomain DED may interact with a single FADD molecule in the DISC. $^{23,33}$ The first DED of the prodomain (blue) may, or may not, interact with each other in the procaspase dimer formed as part of the interdimer assembly and processing mechanism for the procaspases. ${ }^{37,39,40}$ The second DED (dark red) interacts with the FADD DED in a perpendicular orientation ${ }^{23}$

of DISC assembly. This may explain why the procasapses only require dimerization for activation. ${ }^{37,39,40}$ The binding site on FADD for procaspase-8 has recently been described, ${ }^{23}$ which indicates that the interaction may require only one of the procaspase DEDs in a perpendicular arrangement (Figure $6 \mathrm{~d}) .{ }^{23,33}$ As both procaspase DEDs are required for successful recruitment into the DISC, this leaves one DED of the prodomain, along with the catalytic domain, to aid in the formation of the procaspase dimer before activation.

\section{Materials and Methods}

\section{Expression constructs and mutagenesis}

CD95-IC (residues 178-319), TRADD (residues 195-312) ${ }^{24}$ and FADD NT (residues 1-183) were cloned in pGEX4T1 (GE HealthCare). For coupled in vitro transcription/translation FADD, FADD NT, FADD DED (residues 1-88) and FADD DD (residues 89-208) were cloned into pET28b (Novagen). Full-length procaspase-8 C360S was cloned in pET21a (Novagen). ${ }^{26}$

For mammalian cell expression, FADD, FADD DED, FADD DD and DNFADD were cloned in pcDNA3.0 (Invitrogen, Carlsbad, CA, USA). For generation of stable Jurkat cell lines, various FADD mutants and DN-FADD were cloned in the pcDNA3.1Puro. ${ }^{18,19}$ Site-directed mutagenesis of FADD and was carried out using the Quick Change Kit from Stratagene. Full-length FADD was also cloned in the pIRES2-EGFP vector (Clontech). For generation of Tet inducible stable cell lines, DN-FADD, LZ-FADD DD (residues 88-208) and IZ-FADD DD (residues 88-208) were cloned into pcDNA5 FRT/TO (Invitrogen). All FADD constructs in mammalian expression vectors were appended with a C-terminal hemaglutinin $(\mathrm{HA})$ tag.

A diagram illustrating all these constructions is given in Supplement 3.

\section{Proteins}

GST-CD95 IC, GST-FADD NT and GST-TRADD were expressed in BL21 Escherichia coli (Novagen, Madison, WI, USA) and purified on Glutathione-agarose beads (GE HealthCare) according to the manufacturer's instructions. $\left[{ }^{35} \mathrm{~S}\right]-$ Met-labelled proteins were expressed by coupled transcription/translation (Promega) according to the manufacturer's directions.

\section{Reconstitution of CD95/FADD, FADD/FADD and TRADD/FADD/Caspase-8 complexes}

GST-CD95 pull-down assays was performed as described. ${ }^{26}$ For reconstitution of TRADD/FADD/procaspase-8 complexes, $25 \mu \mathrm{l}$ of a $50 \%$ bead slurry of GST-TRADD DD were mixed in $200 \mu$ l binding buffer (50 mM Hepes, pH 7.4, $50 \mathrm{mM} \mathrm{NaCl}, 0.1 \%$ NP-40, $5 \mathrm{mM}$ EDTA, 10\% Glycerol) with $10 \mu$ lof the $\left[{ }^{35} \mathrm{~S}\right]$-labelled FADD mutants and $10 \mu \mathrm{l}$ of the $\left[{ }^{35} \mathrm{~S}\right]$-labelled procaspase- $8 \mathrm{C} 360 \mathrm{~S}$. After $2 \mathrm{~h}$ nutation at $4{ }^{\circ} \mathrm{C}$, the beads were harvested by centrifugation and washed 3 times with $500 \mu \mathrm{l}$ of binding buffer for $10 \mathrm{~min}$ at $4^{\circ} \mathrm{C}$. Associated proteins were eluted with $15 \mu \mathrm{l}$ SDS-PAGE loading dye at $95^{\circ} \mathrm{C}$ and visualized by SDS-Tris/Tricine PAGE and phosphorimaging of the dried gel. GST-FADD-NT wild-type and mutants were used as bait to pull down $\left[{ }^{35} \mathrm{~S}\right]-\mathrm{FADD}$ full-length in a pull-down assay, using the same protocol as above.

\section{Cell culture, transient transfection}

The analysis of FADD DED mutants in MCF7-Fas cells ${ }^{25}$ was performed as previously described. ${ }^{26}$ For analysis of the interaction between FADD domains and CD95, 1-2 $\mu \mathrm{g}$ pcDNA3.0-FADD, -FADD DED, -FADD DD and -DN-FADD were transfected into MCF7-Fas cells with the aid of Fugene 6 reagent (Roche). At $16 \mathrm{~h}$ post transfection, cells were harvested and lysed for $30 \mathrm{~min}$ on ice in lysis buffer $(10 \mathrm{mM}$ Tris-Cl, pH 7.4; $150 \mathrm{mM}$ $\mathrm{NaCl} ; 1 \mathrm{mM}$ EDTA; $1 \mathrm{mM}$ EGTA; 1\% Triton X-100; 0.5\% NP-40; $0.2 \mathrm{mM}$ $\mathrm{Na}_{3} \mathrm{VO}_{4}$ and protease inhibitors mixture (Roche)). The cell lysate was spun down at $14000 \times g$ for $20 \mathrm{~min}$ and the supernatant was saved.

Co-transfection of FADD/DN-FADD, FADD/LZ-FADD DD, FADD/IZFADD DD in MCF7-Fas cells was achieved in $100 \mathrm{~mm}$ Petridishes as 
described above using $0.5 \mu \mathrm{g}$ FADD DNA and increasing amounts of DNFADD, LZ-FADD DD or IZ-FADD DD (1-5 $\mu \mathrm{g}$ DNA). Transient transfection of Jurkat l2.1 cells with full-length FADD and either DN-FADD, LZ-FADDDD or IZ-FADD-DD was achieved with DMRIE-C Reagent (Invitrogen) following the manufacturer's directions. Full-length FADD was expressed from pIRES2-EGFP, whereas DN-FADD, LZ-FADD-DD and IZ-FADD-DD were expressed from pcDNA3.1 (Puro). Typically 10-15\% transfection efficiency was achieved.

\section{Cell culture, stable transfection}

Jurkat $A 3$ and 12.1 cells were stably transfected with various FADD constructs as previously described. ${ }^{18,19}$ Briefly $1 \times 10^{7}$ cells were transfected with $40 \mu \mathrm{g}$ of Pvul linearized pcDNA3.1-Puro $(+)$ vector encoding different FADD mutants/constructs. The cells were electroporated using a Biorad Gene Pulser at $270 \mathrm{~V}$ and $960 \mu \mathrm{F}$ and the cells were selected for puromycin resistance. Expression of the FADD constructs was tested by Western blotting with rabbit anti-FADD polyclonal antibody (Santa Cruz Biotechnology, Inc. Santa Cruz, CA, USA) or an antiHA peroxidase (3F10, Roche Diagnostics, $\mathrm{GmbH}$ ).

For generation of Tet inducible stable cell lines with DN-FADD, LZFADD DD and IZ-FADD DD, $2 \times 10^{6}$ HEK 293 Flip-In TREx (HEK293 F-T) cells (Invitrogen) were co-transfected with $2 \mu \mathrm{g} \mathrm{pcDNA5} \mathrm{FRT/TO} \mathrm{encoding}$ the above-mentioned constructs and $9 \mu \mathrm{g}$ pOG44 vector (Invitrogen) encoding the FLIP recombinase. The transfection was achieved with Fugene 6 reagent. At $48 \mathrm{~h}$ post-transfection, the cells were selected for resistance to $200 \mu \mathrm{g} / \mathrm{ml}$ hygromycin (Sigma-Aldrich, St. Louis, MO, USA) and $5 \mu \mathrm{g} / \mathrm{ml}$ blasticidin S (Sigma-Aldrich). After approximately 1 week, the selection process was completed and most of the cells were dead. Individual antibiotic-resistant clones, which developed after another week, were picked and allowed to grow in individual populations in the presence of $100 \mu \mathrm{g} / \mathrm{ml}$ hygromycin and $5 \mu \mathrm{g} / \mathrm{ml}$ blasticidin S. After two additional weeks, the stable cell lines were fully developed and stored in liquid nitrogen. Expression of FADD constructs was induced with $5 \mu \mathrm{g} / \mathrm{ml}$ tetracycline (Sigma-Aldrich). Clones with similar expression levels of DNFADD, LZ-FADD DD and IZ-FADD DD were used for further studies.

\section{Apoptosis assay}

Assessment of apoptosis in MCF7-Fas cells transfected with FADD mutants was described previously. ${ }^{26}$ For Jurkat 12.1 and $A 3$ cells, $1 \times 10^{6}$ cells $/ \mathrm{ml}$ were treated or $100 \mathrm{ng} / \mathrm{ml}$ TNF $\alpha$ (Apotech, San Diego, CA, USA) and $1 \mu \mathrm{g} / \mathrm{ml}$ cycloheximide (Sigma-Aldrich) for $3 \mathrm{~h}$ at $37^{\circ} \mathrm{C}$. Cells were stained with the FITC conjugated Annexin V (FITC-Annexin V) and propidium iodide (PI) (Sigma-Aldrich). A total of $3 \times 10^{4}$ cells were acquired and analyzed on a FACSCalibur flow cytometer (Becton Dickinson, NJ, USA) using the CellQuest software (BD Biosciences, NJ, USA). Apoptotic cells were quantified as the percentage of cells stained with Annexin V-FITC.

Jurkat I2.1 cells were transiently co-transfected with FADD (expressed from pIRES2-EGFP-FADD vector) and increasing amounts of DN-, LZ-, and IZ-FADD-DD plasmids using the DMRIE-C reagent. At $18 \mathrm{~h}$ posttransfection, the cells were stimulated with FasL $(100 \mathrm{ng} / \mathrm{ml})$ (Apotech) for $3 \mathrm{~h}$ at $37^{\circ} \mathrm{C}$ and stained with Annexin V-Cy3 (Biovision) followed by analysis by flow cytometry. Apoptotic cells were quantified as the percentage of GFP positive cells stained with Annexin V-Cy3. Typically, $3 \times 10^{5}$ GFP positive cells were counted.

Assessment of apoptosis in HEK 293 cells stably transfected with DNFADD, LZ-, IZ-FADD DD was made by Hoechst staining as follows. Expression of FADD constructs was induced with tetracycline for $5 \mathrm{~h}$ followed by activation of programmed cell death with FasL $(100 \mathrm{ng} / \mathrm{ml})$ (Apotech) for $18 \mathrm{~h}$. Cells were stained with $1 \mu \mathrm{g} / \mathrm{ml}$ Hoechst 33354 and inspected by light and fluorescence microscopy. Apoptotic cells were characterized by change in cell morphology, cells shrinking and becoming rounded as well as visible membrane blebbing. Apoptotic cells were pronounced fluorescent upon Hoechst staining compared to live cells. Viable cells by contrast, kept the elongated shape and spreading to the plate as well as low Hoechst staining.

\section{Co-immunoprecipitation}

A total of $1.5 \times 10^{6}$ MCF7-Fas cells, used for immunoprecipitation, were plated in $100 \mathrm{~mm}$ plates and transfected as described above. At $18 \mathrm{~h}$ posttransfection, the cells were washed with PBS and treated with $3 \mu \mathrm{g} \mathrm{Apo}$ 1-3 antibody for $10 \mathrm{~min}$. The cells were harvested and lysed in $1 \mathrm{ml}$ lysis buffer and incubated for 10 min on ice. The crude extracts were spun down in a bench centrifuge for $20 \mathrm{~min}$ at $13000 \times g$ and the supernatant was further used for immunoprecipitation.

Immunoprecipitation of the CD95 with FADD, FADD DED, FADD DD, DN-FADD FADD/DN-, LZ-, IZ-FADD was performed using $900 \mu \mathrm{l}$ cell lysate incubated with $10 \mu \mathrm{l}$ Protein A-Magnetic Beads (New England Biolabs) and nutated for $2 \mathrm{~h}$ at $4^{\circ} \mathrm{C}$. The beads were washed four times with $1 \mathrm{ml}$ lysis buffer for $10 \mathrm{~min}$ and the beads were eluted with $40 \mu \mathrm{l} 0.1 \mathrm{M}$ glycine buffer $\mathrm{pH} 2.8$. The IP fractions were neutralized with $4 \mu \mathrm{l} 1 \mathrm{M}$ Tris $\mathrm{pH} 8.0$, followed by addition of $20 \mu \mathrm{l}$ SDS-sample dye and boiling at $95^{\circ} \mathrm{C}$ for 2 min. Typically, $15 \mu \mathrm{l}$ of an IP fraction was used for western blotting. Alternatively, the beads were resuspended directly in $30 \mu$ of SDS-sample dye and boiled for $2 \mathrm{~min}$ at $95^{\circ} \mathrm{C}$. $12 \%$ SDS-Tris-tricine gels were run at $120 \mathrm{~V}$ for $90 \mathrm{~min}$, which leave the phosphorylated and unphosphorylated forms of FADD unresolved in the gel. Figure 4 a suggests that the presence of the unstructured tail of FADD, which includes residues 192-208 and the phosphorylation site, are dispensable for the interaction with FADD and procaspase-8.

To determine the DN-FADD transgene and endogenous FADD expression levels in mouse thymocytes, C57BL/6J or DN-FADD (Tg(Lck-FADD)1Hed) thymocytes were lysed in $150 \mathrm{mM} \mathrm{NaCl}, 50 \mathrm{mM}$ $\mathrm{NaF}, 10 \mathrm{mM}$ b-glycerophosphate, $20 \mathrm{mM}$ HEPES pH 7.4, 1\% Triton X-100, $1 \mathrm{mM}$ PMSF, $1 \mathrm{mg} / \mathrm{ml}$ Aprotinin, $1 \mathrm{mg} / \mathrm{ml}$ Leupeptin and $1 \mathrm{mM}$ $\mathrm{NaVO}_{4}$. Protein lysates were quantified using Bradford assays (BioRad, Hercules, CA, USA), resolved by SDS-PAGE and transferred onto polyvinylidene difluoride membranes (PVDF; Millipore, Bedford, MA, USA). The blot was probed with anti-FADD antibody (Upstate Biotechnology).

\section{Acknowledgements}

We thank Vishva Dixit, Michael Lenardo and Marcus Peter for cDNAs of human CD95 and FADD, Marcus Peter for MCF7-FAS cells and antibodies. We thank Marcus Peter, Doug Green and Vishva Dixit for many useful discussions. We thank Andrew Thorburn and Lance $R$. Thomas for TRADD cDNA, pcDNA3.1 Puro vectors, Jurkat A3, I2.1 cell lines and for useful discussions. This work was supported in part by fellowships from the Human Frontier Science Program (LT0537), the NHMRC of Australia (997045) and the Norman and Rosita Winston Foundation to J.M.H., and by the National Science Foundation, the National Institutes of Health and Irma T. Hirschl Trust grants to MHW. M.HW is a Distinguished Young Scholar of the W.M. Keck Foundation. 


\section{References}

1. Chinnaiyan AM, O'Rourke K, Tewari M and Dixit VM (1995) FADD, a novel death domain-containing protein, interacts with the death domain of Fas and initiates apoptosis. Cell 81: 505-512

2. Boldin MP, Varfolomeev EE, Pancer Z, Mett IL, Camonis JH and Wallach D (1995a) A novel protein that interacts with the death domain of Fas/APO1 contains a sequence motif related to the death domain. J. Biol. Chem. 270: 7795-7798.

3. Eberstadt M, Huang BH, Chen ZH, Meadows RP, Ng SC, Zheng LX, Lenardo MJ and Fesik SW (1998) NMR structure and mutagenesis of the FADD (Mort1) death-effector domain. Nature 392: 941-945.

4. Jeong EJ, Bang S, Lee TH, Park YI, Sim WS and Kim KS (1999) The solution structure of FADD death domain. Structural basis of death domain interactions of Fas and FADD. J. Biol. Chem. 274: 16337-16342.

5. Berglund $H$, Olerenshaw D, Sankar A, Federwisch M, McDonald NQ and Driscoll PC (2000) The three-dimensional solution structure and dynamic properties of the human FADD death domain. J. Mol. Biol. 302: 171-188.

6. Fesik SW (2000) Insights into programmed cell death through structural biology. Cell 103: 273-282.

7. Muzio M, Chinnaiyan AM, Kischkel FC, O'Rourke K, Shevchenko A, Ni J, Scaffidi C, Bretz JD, Zhang M, Gentz R, Mann M, Krammer PH, Peter ME and Dixit VM (1996) FLICE, a novel FADD-homologous ICE/CED-3-like protease, is recruited to the CD95 (Fas/APO-1) death-inducing signaling complex. Cell 85: 817-827.

8. Boldin MP, Goncharov TM, Goltsev YV and Wallach D (1996) Involvement of $\mathrm{MACH}$, a novel MORT1/FADD-interacting protease, in Fas/APO-1- and TNF receptor-induced cell death. Cell 85: 803-815.

9. Kischkel FC, Lawrence DA, Tinel A, LeBlanc H, Virmani A, Schow P, Gazdar A, Blenis J, Arnott D and Ashkenazi A (2001) Death receptor recruitment of endogenous caspase-10 and apoptosis initiation in the absence of caspase-8. J. Biol. Chem. 276: 46639-46646.

10. Wang J, Chun HJ, Wong W, Spencer DM and Lenardo MJ (2001) Caspase-10 is an initiator caspase in death receptor signaling. Proc. Natl. Acad. Sci. USA 98: $13884-13888$

11. Ashkenazi A and Dixit VM (1998) Death receptors: signaling and modulation. Science 281: 1305-1308.

12. Scaffidi C, Fulda S, Srinivasan A, Friesen C, Li F, Tomaselli KJ, Debatin KM, Krammer PH and Peter ME (1998) Two CD95 (APO-1/Fas) signaling pathways. EMBO J. 17: 1675-1687.

13. Banner DW, D’Arcy A, Janes W, Gentz R, Schoenfeld H-J, Broger C, Loetscher $\mathrm{H}$ and Lesslauer W (1993) Crystal structure of the soluble human $55 \mathrm{kD}$ TNF receptor-human TNF complex: implications for TNF receptor activation. Cell 73: $431-445$.

14. Hymowitz SG, Christinger HW, Fuh G, Ultsch M, O'Connell M, Kelley RF, Ashkenazi A and de Vos AM (1999) Triggering cell death: the crystal structure of Apo2L/TRAIL in a complex with death receptor 5. Mol. Cell 4: 563-571.

15. Mongkolsapaya J, Grimes JM, Chen N, Xu XN, Stuart DI, Jones EY and Screaton GR (1999) Structure of the TRAIL-DR5 complex reveals mechanisms conferring specificity in apoptotic initiation. Nat. Struct. Biol. 6: 1048-1053.

16. Chinnaiyan AM, Tepper CG, Seldin MF, O'Rourke K, Kischkel FC, Hellbardt S, Krammer PH, Peter ME and Dixit VM (1996) FADD/MORT1 is a common mediator of CD95 (Fas/APO-1) and tumor necrosis factor receptor-induced apoptosis. J. Biol. Chem. 271: 4961-4965.

17. Zhang $J$ and Winoto A (1996) A mouse Fas-associated protein with homology to the human Mort1/FADD protein is essential for Fas-induced apoptosis. Mol. Cell. Biol. 16: 2756-2763.

18. Thomas LR, Stillman DJ and Thorburn A (2002) Regulation of FADD death domain interactions by the death effector domain identified by a modified reverse two-hybrid screen. J. Biol. Chem. 277: 34343-34348.

19. Thomas LR, Henson A, Reed JC, Salsbury FR and Thorburn A (2004) Direct binding of Fas-associated death domain (FADD) to the tumor necrosis factorrelated apoptosis-inducing ligand receptor DR5 is regulated by the death effector domain of FADD. J. Biol. Chem. 279: 32780-32785.

20. Newton K, Harris AW, Bath ML, Smith KGC and Strasser A (1998) A dominan interfering mutant of FADD/MORT1 enhances deletion of autoreactive thymocytes and inhibits proliferation of mature T lymphocytes. EMBO J. 17: 706-718.

21. Walsh CM, Wen BG, Chinnaiyan AM, O'Rourke K, Dixit VM and Hedrick SM (1998) A role for FADD in T cell activation and development. Immunity 8: 439449.

22. Zörnig M, Hueber A-O and Evan G (1998) p53-dependent impairment of T-cell proliferation in FADD dominant-negative transgenic mice. Curr. Biol. 8: 467-470.

23. Carrington PE, Sandu C, Wei YF, Hill JM, Morisawa G, Huang T, Gavathiotis E, Wei $Y$ and Werner MH (2005) The three-dimensional structure of FADD defines the relative organization of death receptor and procaspase in the deathinducing signaling complex. Mol. Cell (in press).

24. Sandu C, Gavathiotis E, Huang T, Wegorzewska I and Werner MH (2005) A mechanism for death receptor discrimination by death adaptors. J. Biol. Chem. 280: 31974-31980

25. Jaattela M, Benedict M, Tewari M, Shayman JA and Dixit VM (1995) Bcl-x and $\mathrm{Bcl}-2$ inhibit TNF and Fas-induced apoptosis and activation of phospholipase A2 in breast carcinoma cells. Oncogene 10: 2297-2305.

26. Hill JM, Morisawa G, Kim T, Huang T, Wei Y, Wei YF and Werner MH (2004) Identification of an expanded binding surface on the FADD death domain responsible for interaction with CD95/Fas. J. Biol. Chem. 279: 1474-1481.

27. Kaufmann M, Bozic D, Briand C, Bodmer JL, Zerbe O, Kohl A, Tschopp J and Grutter MG (2002) Identification of a basic surface area of the FADD death effector domain critical for apoptotic signaling. FEBS Lett. 527: 250-254.

28. Micheau $O$ and Tschopp J (2003) Induction of TNF receptor I-mediated apoptosis via two sequential signaling complexes. Cell 114: 181-190.

29. Harbury PB, Alber T and Kim PS (1994) Crystal structure of an isoleucine zipper trimer. Nature 371: 80-83.

30. Bang S-H, Jeong E-J, Kim I-K, Jung Y-K and Kim K-S (2000) Fas- and tumor necrosis factor-mediated apoptosis uses the same binding surface of FADD to trigger signal transduction. J. Biol. Chem. 275: 36217-36222.

31. Siegel RM, Muppidi JR, Sarker M, Lobito A, Jen M, Martin D, Straus SE and Lenardo MJ (2004) SPOTS: signaling protein oligomeric transduction structures are early mediators of death receptor-induced apoptosis at the plasma membrane. J. Cell. Biol. 167: 735-744.

32. Henkler F, Behrle E, Dennehy KM, Wicovsky A, Peters N, Warnke C, Pfizenmaier K and Wajant $\mathrm{H}$ (2005) Extracellular domains of FasL and Fas are sufficient for the formation of supramolecular FasL-Fas clusters of high stability. J. Cell. Biol. 168: 1087-1098.

33. Yang JK, Wang L, Zheng L, Wan F, Ahmed M, Lenardo MJ and Wu H (2005) Crystal structure of MC159 reveals molecular mechanism of DISC assembly and FLIP inhibition. Mol. Cell. 20: 939-949.

34. Li FY, Jeffrey PD, Yu JW and Shi Y (2005) Crystal structure of a Viral FLIP: insights into FLIP-mediated inhibition of death receptor signaling. J. Biol. Chem. 281: 2960-2968

35. Muppidi JR, Lobito AA, Ramaswamy M, Yang JK, Wang L, Wu H and Siegel RM (2006) Homotypic FADD interactions through a conserved RXDLL motif are required for death receptor-induced apoptosis. Cell Death Differ. 20 January 2006 [Epub ahead of print].

36. Hill JM, Ramos J, Ginsberg M and Werner MH (2002) The interaction of the death motif protein PEA-15 with ERK MAP kinase reveals a common docking site for protein interaction with the death domain/death effector domain fold. EMBO J. 21: 6494-6504.

37. Chang DW, Xing Z, Capacio VL, Peter ME and Yang X (2003) Interdimer processing mechanism of procaspase-8 activation. EMBO J. 22: 4132-4142.

38. Holler N, Tardivel A, Kovacsovics-Bankowski M, Hertig M, Gaide O, Martinon F, Tinel A, Deperthes D, Calderara S, Schulthess T, Engel J, Schneider P and Tschopp J (2003) Two adjacent trimeric Fas ligands are required for Fas signaling and formation of a death-inducing signaling complex. Mol. Cell. Biol. 23: $1428-1440$.

39. Muzio M, Stockwell BR, Stennicke HR, Salvesen GS and Dixit VM (1998) An induced proximity model for caspase-8 activation. J. Biol. Chem. 273: 29262930.

40. Salvesen GS and Dixit VM (1999) Caspase activation: the induced-proximity model. Proc. Natl. Acad. Sci. USA 96: 10964-10967. 